\title{
Effects of vegetable cultivation on health: A qualitative study of the health effects other than increasing vegetable intake
}

\author{
Daisuke Machida ${ }^{*}$, Tohru Yoshida ${ }^{2}$ \\ 1 Takasaki University of Health and Welfare; machida-d@takasaki-u.ac.jp \\ 2 Jumonji University; t-yosida@jumonji-u.ac.jp \\ * Correspondence: machida-d@takasaki-u.ac.jp; Tel.: (+81-27-352-1290)
}

\begin{abstract}
The present short communication aimed to determine the effects of vegetable cultivation on health. We conducted a qualitative study using responses to an open-ended question that was part of a survey on regional differences on vegetable intake. Participants in this study were residents of Gunma Prefecture, Japan, and were aged between 20-74 years. In the questionnaire, we asked: "Aside from increasing vegetable intake, how does vegetable cultivation affect your health?" We were able to categorize the answers into six subcategories related to physical health, mental health, and social well-being.
\end{abstract}

Keywords: vegetable cultivation; health; physical health; mental health; social well-being; qualitative study; adult; Japan

\section{Introduction}

Horticultural activities such as vegetable gardening are known to promote physical, mental, and emotional health among adult community dwellers. Alaimo et al. in their research study conducted a narrative review of studies showing the health effects of participation in community gardens and confirmed various positive effects including increased physical activity, greater social capital, increased vegetable intake, and decreased $\mathrm{HbA1C}$ [1]. Soga et al. in their study conducted a metaanalysis of the association between gardening and health or healthy lifestyles such as physical activity and found that gardening was significantly related to health and healthy lifestyles [2].

Nevertheless, there are relatively few reports to date on the relationship among adults in Japan between horticultural activities and health. Machida et al. and Soga et al. in these studies have examined the relationship between community garden participation and vegetable intake, self-rated health, body mass index, mental health, physical activity, and social capital [3,4]. Sugiura et al. in their study have clarified that elderly farmers report less stress than other elderly people, and also that many of them identify cultivating as a motivation for living [5]. However, the only study to date that has qualitatively extracted the health effects of horticultural activities was a report by Hamada et al., which, having only 36 participants, may not have had sufficient statistical power to extract all effects [6].

In this short communication, we qualitatively examine the health effects of vegetable cultivation as reported by the vegetable cultivators. Our findings can be used in future research and practices of health promotion through horticultural activities.

\section{Materials and Methods}

\subsection{Study participants and methods}

Data collection from this survey has been described in our previous studies [7, 8]. The participants in this study were residents aged 20-74 living in three segments (rural, suburban, and urban) of a city in Gunma Prefecture, Japan. The survey data were collected using a self-administered 
questionnaire between September 2016 and October 2016. Two copies of the questionnaire were mailed to each of the 2,260 households in the three regions. Town Plus (Japan Post Co., Ltd.) handled the mailing (September 12, 2016). This service enables senders to have mail delivered to all households in a designated area without knowing the specific addresses of the participants. The questionnaires were numbered to enable us to identify which of the three regions each response came from. If a household had no residents aged 20-74 years, the recipients did not need to reply. If a household had three or more 20-74-year-old residents, it was acceptable for two people to reply. The questionnaire explained that responding was optional.

\subsection{Survey tool}

The questionnaire consisted of 14 questions about basic characteristics that were directed to all participants, and nine questions that were directed to vegetable cultivators only about topics such as cultivation style. The question about the health effects of vegetable cultivation was directed to vegetable cultivators only. This open-ended question was: "Do you think that any health benefits other than increased vegetable intake come from engaging in vegetable cultivation?" We included the phrase "other than increased vegetable intake" in this question because our survey was conducted mainly to examine the relationship between vegetable cultivation and vegetable intake $[8$, 9]. Therefore, several other survey items examined the relationship between vegetable cultivation and vegetable intake. The main aim of the present study, however, was to explore the health effects of vegetable cultivation other than increased vegetable intake. In response to the question: "Do you think that any health benefits come from engaging in vegetable cultivation?," in the absence of the phrase "other than increased vegetable intake," we expected that many participants would answer "increased vegetable intake" as the topic was fresh in their minds because of the nature of the other questions and may not have identified any other health benefits of vegetable cultivation.

Additionally, the following eight items were included to assess the basic characteristics of participants: sex (female or male); age (20-29, 30-39, 40-49, 50-59, 60-69, 70-74); family structure (living alone, living together); educational background (elementary or junior high school, high school, vocational or junior college, and university or graduate school); employment status (unemployed or retired, part-time worker, and full-time worker); cultivation style (farmer, home gardener, community gardener, and other); cultivation frequency (less than one day in two weeks, one day in two weeks, one to two days in a week, three to five days in a week, and six to seven days in a week).

\subsection{Analyses}

As in our previous study [6], the results of the open-ended questionnaire were collected and classified with reference to the World Health Organization's (WHO) health definitions [9]. Firstly, the descriptive content was segmented into single findings, and the health effects of vegetable cultivation other than vegetable intake were extracted from the segmented information, codes were created, and code collection subcategories with similar contents were created. Furthermore, the created subcategories were applied to the WHO's definitions of physical health, mental health, and social well-being [9]. In order to ensure subcategory validity, we repeated each series of classifications several times. The number of occurrences of each code was also counted.

\subsection{Ethical approval}

This study was approved by the Gunma University Ethical Review Board for Medical Research Involving Human Subjects (Submission No.160074, approved August 16, 2016).

\section{Results}

We mailed questionnaires to 2,260 households and obtained responses from 586 households (household response rate: 25.9\%). A total of 873 participants (rural: 293, suburban: 295, urban: 285) answered. Of the 873 participants, we anticipated 421 participants as being those who did not 
cultivate vegetables and used the remaining 452 in our analysis. The distribution of responses is shown in Table 1.

Table 1. Distribution of responses.

\begin{tabular}{|c|c|c|c|c|c|}
\hline & $\mathrm{n}$ & $\%$ & & $\mathrm{n}$ & $\%$ \\
\hline area & & & employment status & & \\
\hline rural & 225 & 50 & unemployed or retired & 174 & 38 \\
\hline suburban & 175 & 39 & part-time worker & 68 & 15 \\
\hline urban & 52 & 11 & full-time worker & 190 & 42 \\
\hline $\operatorname{sex}$ & & & no response & 20 & 4 \\
\hline woman & 250 & 55 & cultivation style (multiple answer) & & \\
\hline man & 199 & 44 & farmer & 127 & 28 \\
\hline no response & 3 & 1 & home gardener & 321 & 71 \\
\hline age & & & community gardener & 3 & 1 \\
\hline $20-29$ & 12 & 3 & other & 12 & 3 \\
\hline $30-39$ & 30 & 7 & no response & 10 & 2 \\
\hline $40-49$ & 57 & 13 & cultivation frequency & & \\
\hline $50-59$ & 93 & 21 & less than 1 day in 2 weeks & 46 & 10 \\
\hline $60-69$ & 173 & 38 & 1 day in 2 weeks & 49 & 11 \\
\hline 70 or more & 85 & 19 & 1 to 2 days in a week & 155 & 34 \\
\hline no response & 2 & 0 & 3 to 5 days in a week & 106 & 23 \\
\hline family structure & & & 6 to 7 days in a week & 79 & 17 \\
\hline living alone & 38 & 8 & no response & 17 & 4 \\
\hline living together & 410 & 91 & & & \\
\hline no response & 4 & 1 & & & \\
\hline \multicolumn{6}{|l|}{ educational background } \\
\hline elementary or junior high school & 49 & 11 & & & \\
\hline high school & 206 & 46 & & & \\
\hline vocational or junior college & 105 & 23 & & & \\
\hline university or graduate school & 74 & 16 & & & \\
\hline no response & 18 & 4 & & & \\
\hline
\end{tabular}

Responses to the question about the health benefits of vegetable cultivation are presented in

Table 2. We grouped the responses into six subcategories (maintenance and improvement of physical condition, promotion of a healthy lifestyle, improvement of mood, exposure to nature, providing reasons for living, and enhancing social well-being) from among 27 codes. "Maintenance and improvement of physical condition" and "promotion of a healthy lifestyle" were classified as physical health benefits. "Improvement of mood," "exposure to nature," and "providing a reason for living" were classified as mental health benefits. Social well-being benefits were grouped into a single subcategory. 
Table 2. Effects of vegetable cultivation on health.

\begin{tabular}{|c|c|c|c|c|}
\hline categories & subcategories & codes & $\mathrm{n}$ & $\%$ \\
\hline \multirow{10}{*}{ physical health } & \multirow{5}{*}{$\begin{array}{l}\text { maintenance and } \\
\text { improvement of physical } \\
\text { condition }\end{array}$} & decreased blood pressure & 1 & 0.2 \\
\hline & & weight management & 2 & 0.4 \\
\hline & & physical fitness improvement & 19 & 4.2 \\
\hline & & constipation prevention & 6 & 1.3 \\
\hline & & dementia prevention & 7 & 1.5 \\
\hline & \multirow{5}{*}{$\begin{array}{l}\text { promotion of a healthy } \\
\text { lifestyle }\end{array}$} & using my brain & 18 & 4.0 \\
\hline & & using my fingertips & 1 & 0.2 \\
\hline & & moving my body & 155 & 34.3 \\
\hline & & taking care of my health & 3 & 0.7 \\
\hline & & providing a regular rhythm in life & 6 & 1.3 \\
\hline \multirow{16}{*}{ mental health } & \multirow{5}{*}{ improvement of mood } & stress reduction & 20 & 4.4 \\
\hline & & peace of mind & 11 & 2.4 \\
\hline & & cheering me up & 3 & 0.7 \\
\hline & & good feeling & 4 & 0.9 \\
\hline & & change of mood & 18 & 4.0 \\
\hline & \multirow{5}{*}{ exposure to nature } & increased time in the sun & 13 & 2.9 \\
\hline & & increased exposure to clean air & 1 & 0.2 \\
\hline & & experiencing the seasons & 7 & 1.5 \\
\hline & & contact with the soil & 6 & 1.3 \\
\hline & & interaction with nature & 8 & 1.8 \\
\hline & \multirow{6}{*}{$\begin{array}{l}\text { providing reasons for } \\
\text { living }\end{array}$} & $\begin{array}{l}\text { the pleasure of sharing vegetables with } \\
\text { family and friends }\end{array}$ & 5 & 1.1 \\
\hline & & feeling satisfied & 11 & 2.4 \\
\hline & & taking an interest in an activity & 3 & 0.7 \\
\hline & & fun and joy & 46 & 10.2 \\
\hline & & enriches my heart & 4 & 0.9 \\
\hline & & providing reasons for living & 4 & 0.9 \\
\hline \multirow{3}{*}{\multicolumn{2}{|c|}{ social well-being }} & work (social participation) & 5 & 1.1 \\
\hline & & interaction with family and neighbors & 16 & 3.5 \\
\hline & & going outside & 13 & 2.9 \\
\hline
\end{tabular}

\section{Discussion}

In this study, we examined the effects of vegetable cultivation on health qualitatively. We were able to categorize the responses into the following six subcategories: maintenance and improvement of physical condition; promotion of a healthy lifestyle; improvement of mood; exposure to nature; providing reasons for living; and social well-being. "Maintenance and improvement of physical condition" and "promotion of a healthy lifestyle" were classified as physical health benefits, while 
"improvement of mood," "exposure to nature," and "providing reasons for living" were classified as mental health benefits, with social health benefits in their own subcategory. No previous report has qualitatively evaluated the health effects of horticulture and cultivation for such a large population of participants in Japan. Therefore, this report may be useful for future research and practice. Additionally, many of the identified effects of horticulture and cultivation have been confirmed in previous studies in Japanese populations and in other populations all over the world [1-6], and are in keeping with commonsense interpretations. Accordingly, we believe that promoting vegetable cultivation will help improve general health. This will require the availability of sufficient space for cultivation in urban, suburban, and rural areas. At present, there is abundant space for vegetable cultivation in the rural areas of Japan. It would be useful for us to regard the development of these cultivation spaces as a resource that contributes to health. These environments must be maintained and used to promote the health of local residents.

This study had some limitations. Firstly, the methodology was only qualitative. Quantitative studies are needed to explore the findings more thoroughly. Additionally, the data cannot be said to be theoretically saturated, as we did not use gradual theoretical sampling. One of the strengths of the study was that we were able to incorporate data from people with a wide variety of characteristics and lifestyles such as ages, cultivation styles, and type of geographic area.

Author Contributions: conceptualization, M.D. and Y.T.; methodology, M.D. and Y.T.; formal analysis, M.D.; investigation, M.D. and Y.T.; writing-original draft preparation, M.D.; supervision, Y.T.; project administration, M.D.; funding acquisition, M.D.

Funding: This research was funded by the Nakatani Suzuyo Memorial Fund for Nutrition and Dietetics.

Acknowledgments: The authors would like to thank Enago (www.enago.jp) for the English language review.

Conflicts of Interest: The authors declare no conflict of interest.

\section{References}

1. Alaimo, K.; Beavers, A.W.; Crawford, C.; Snyder, E.H.; Litt, J.S. Amplifying health through community gardens: A framework for advancing multicomponent, behaviorally based neighborhood interventions. Curr Environ Health Rep. 2016, 3, 302-312. doi: 10.1007/s40572-016-0105-0.

2. Soga, M.; Gaston, K.J;; Yamaura, Y.; Gardening is beneficial for health: A meta-analysis. Prev Med Rep. 2016, 14, 5, 92-99. doi: 10.1016/j.pmedr.2016.11.007.

3. Machida, D.; Yoshida, T. Relationship between fruit and vegetable gardening and health-related factors: Male community gardeners aged 50-74 years living in a suburban area of Japan. Nihon Koshueisei Zasshi 2017, 64, 684-694 (in Japanese, abstract in English). doi: 10.11236/jph.64.11_684.

4. Soga, M.; Cox, D.T.; Yamaura, Y.; Gaston, K.J.; Kurisu, K.; Hanaki, K. Health benefits of urban allotment gardening: Improved physical and psychological well-being and social integration. Int J Environ Res Public Health. 2017, 14, pii: E71. doi: 10.3390/ijerph14010071.

5. Sugiura, Y.; Sakamoto, J. An agricultural potential for health promotion through the health characteristics of elderly people who have engaged in agriculture. Noson Keikaku Gakkaishi 2007, 26, 389-394. (in Japanese, abstract in English). doi: 10.2750/arp.26.389.

6. Hamada, M.; Iida, A.; Yokohari, M. Influences of urban farming on the health of older people: Differences between individual farming and group farming. Toshi Keikaku Ronbunshu, 2016, 51, 1024-1029. (in Japanese, abstract in English). doi: 10.11361/journalcpij.51.1024.

7. Machida, D.; Yoshida, T. Vegetable intake frequency is higher among rural than among urban or suburban residents, and is partially related to vegetable cultivation, receiving, and purchasing at farmers' markets: A cross-sectional study in a city within Gunma, Japan. JRM 2018, 13, 116-123. doi: 10.2185/jrm.2960.

8. Machida, D.; Yoshida, T. Negative association of vegetable cultivation with the proportion of severely insufficient vegetable intake both directly and indirectly: A cross-sectional study in a city in Gunma, Japan. JRM 2018, 1,: 160-167. doi: 10.2185/jrm.2966.

9. World Health Organization. Constitution. http://www.who.int/about/mission/en/. (March 20, 2019). 